\title{
The Media Literacy Education of Journalism Students Based on Media Criticism Course
}

\author{
Xiaorui Li \\ School of Communication \\ Mianyang Teachers' College \\ Mianyang, China
}

\begin{abstract}
Contemporary college students grow up accompanied by electronic media, as a result, media literacy education is particularly necessary for them. And the media literacy requirement for the journalism students is much higher due to their special professional background. This paper discusses the possibility of combining journalism course education and media literacy education from the integration development of the two, hoping to conduct effective media literacy education while performing professional education through such mutual aid education model, so as to achieve education effect with less effort.
\end{abstract}

Keywords-journalism students; Media Criticism course; media literacy education; possibility

\section{INTRODUCTION}

With the constant development of media, there are increasingly higher requirements for the journalists in the society, especially for the college journalism students, the basic editorial skills can no longer meet the needs of society and the development of the industry. From the current development of media in China, the media literacy level is more and more important for the journalists; and for the college journalism students, this is not only the requirements for students by the specialty itself, but also the requirements for contemporary college students of the industry development. As a result, in the college journalism education, integrating media literacy education into the teaching of this major course is particularly necessary. But from the current situation of media literacy education in colleges, there are very few schools that open such a course. And for the journalism education, this course overlaps with many other courses of this specialty in terms of education objectives. Therefore, it is very necessary to discuss the possibility between media literacy education and journalism course teaching in terms of operation. This paper analyzes the possibility of integrating media literacy education into journalism course with the journalism education of Mianyang Teachers' College as the blueprint.

\section{MEDIA LITERACY EDUCATION AND MEDIA CRITICISM COURSE}

\section{A. Media Literacy and Its Education}

First, confirm that you have the correct template for your paper size. This template has been tailored for output on the
A4 paper size. If you are using US letter-sized paper, please close this file and download the file "MSW_USltr_format".

The British people took the leading in proposing the concept of media literacy in the 1930s, afterwards, the researches about media literacy appeared in America and European countries. But this concept was not introduced to China until the late 1990s. Although media literacy has existed in China for decades, and a large number of scholars have also conducted relevant researches on it during that period, so far, there is still no uniform definition about the concept of media literacy in China. We can discover from many concepts that all concepts involve the interpretation of media information, application of media function, the query of media and other key contents. Therefore, in general, media literacy refers to the public's interpretation and critical ability of various media information as well as the ability of using media information to their personal life and social development, specifically including the ability of selecting, interpreting, evaluating, querying, creating and criticizing of media information. [1]

Media literacy education is also called media quality education, which is originally proposed by the British scholars. In 1933, British scholars F.R.Leavis and Thompson published the book Culture and Environment: Cultivation of Critical Consciousness in cooperation. This book contains the opinion that the popular culture spread by the emerging radio, television and other mass media often promotes a "low level of satisfaction" under the stimulation of commercial motives. Such low level of satisfaction will mislead the spiritual pursuit of members of society, and especially will generate various negative effects on the adolescent growth. As a result, they offer a special exposition against the problem of introducing media quality education into school in the book for the first time, and put forward systematic teaching suggestions. [2] After decades of development, media literacy education has penetrated into various stages of education, especially in the primary and secondary education, as basic education in Britain, the United States, Japan, Canada and other countries, and has developed forward gradually to the stages of Education for All and Lifelong Education. In China, media literacy education is a late starter, and the level of public's understanding of media literacy is still very low. As a result, the better development of domestic media literacy education is in college stage. 


\section{B. Media Criticism Course}

The social activity of media criticism appears accompanied by the development of media in China. With the acceleration of media integration process in China, the development of selfmedia presents an exuberant picture. In addition, "Micro Era" has also penetrated into every aspect of our life in subtle way. The rapid development of media and the role of it in social life require the social members, especially the journalism students, to have certain ability of analysis and identity of media and its related factors. Therefore, the School of Communication of Mianyang Teachers' College opens the Media Criticism course specifically in the education program.

As the compulsory course of journalism students, Media Criticism is generally set for the higher grade students majored in journalism. This course is mainly about what is media criticism, why the course of media criticism is opened, what are the faults that arouse high social participation into criticism in the current media of China and what is the root of the faults, the methods of conducting media criticism etc. As a course with strong comprehensiveness and practice, it requires students to have certain knowledge of journalism and communication as the basis, and analyze and interpret media on the basis of that. This course aims to cultivate students' ability of analysis and judgment of media, media behavior, media content, media practitioners and other factors relating to media, so as to train students' critical consciousness. As the important content of media literacy, such critical consciousness has been recognized by many professionals in the academy and industry.

\section{PRESENT SituAtion OF MEDia Literacy EdUCATION FOR JOURNALISM STUDENTS}

The journalism education in colleges is the direct platform to cultivate future media practitioners, journalism students control the development direction of China's media, so their media literacy level should be the problem concerned by journalism educator, journalism practitioners and even the public. As a teacher in journalism, I have a profound understanding in the teaching process that although the journalism students now have longer contact time with, wider scope and more content of the media, compared with other non-professional students, the information obtained between them from the media or the ability of them in analyzing, judging and using the media content has no obvious difference. From the professional perspective, currently the journalism students in our school generally have low media literacy.

\section{A. Lack of Understanding}

The problem existing in the journalism students of many domestic colleges is insufficient understanding of the theoretical knowledge of media literacy. With respect to our school, its reason can be analyzed from the following two points: first, no special media literacy education course is set up; second, from the structure of journalism students, most students are transfers with few students filling their first choice of this major. Based on the above two points, it can be easily analyzed that students have little understanding of this specialty prior to enrollment, and the admission of this specialty is different from that of the Art, as it is a targeted specialty. As a result, students are short of specialty understanding and the interest of learning this specialty hasn't been cultivated after they are transferred to this specialty. As a result, they have no obvious behavior of active learning of professional knowledge in the earlier stage, let alone media literacy.

\section{B. Low Theory Level}

As part of the professional education content of journalism, media literacy education has not been protected appropriately in the specific education implementation process. As the comprehensive education, media literacy education is carried out on the basis of many professional courses relating to journalism and communication. Therefore, the insufficient basic education will affect the education result directly. Our school focuses on the cultivation of students' journalism consciousness and editing ability at the time of formulating the cultivation program of this specialty according to schoolrunning reality. But the education of students' media literacy is insufficient, leading to the insufficient media literacy knowledge and generally low theoretical level of these students.

\section{Lack of Practice Opportunities}

For the students, media literacy is a kind of covert ability, which is not obvious in the daily professional learning. As a result, some scholars have suggested that personal participation in making media content by the students themselves is the best method to improve media appreciation ability and resist bad media content. Although our school pays attention to the cooperation between college and local education governments, has conducted various school-media cooperation, and arranged students to perform the replacement internship in media sector in winter and summer vacations, students have few opportunities to personally participate in the production process of media product and experience the media agency operation process in the actual teaching process due to lack of corresponding practice platform, and thus they have few changes to improve media literacy in practice.

\section{STRENGTHEN THE POSSIBILITY OF MEDIA LiteraCY EDUCATION THROUGH MEDIA CRITICISM COURSE}

There is a close relationship between Media Criticism course and media literacy education, which relationship is reflected at least in the following aspects: first, both of them are the research about the relationship between media and people; no matter the Media Criticism or media literacy education, they research the relationship between "peoplemedia", which is people-oriented, to reach the purpose of understanding and using the media; second, both of them are the cultivation about people's literacy. A common research carrier-media exists between media literacy education. As a result, the two kinds of literacy have pretty obvious intersection even though differences exist between them.

\section{A. Integration in Terms of Content}

From the perspective of content, Media Criticism mainly lies in the cultivation of students' ability of understanding the media, media work, media behavior and the ability of using 
media. We can feel the relevance between it and the media literacy education quiet intuitively just from the course name, in addition, this course focuses on "criticism". Here, the "criticism" is not what we understand the negation and blame in the traditional sense, but focuses on analysis and evaluation. From this point of view, this is exactly the content of media literacy education.

This course involves many media criticism method, criticism theory, norms and standards of criticism, learning these contents is conducive to strengthen students' understanding and using of media; in media literacy education, however, the cultivation of students' ability of understanding, evaluating and criticizing is the major target. They have quite high integration no matter from the perspective of cultivation goal or the teaching content.

\section{B. Complementarity in Terms of Form}

As the compulsory course of journalism students, Media Criticism can arrange the theory class hour and practice class hour according to the needs of actual teaching in terms of teaching design. The learning of this course mainly adopts the method of combining theory and practice. But in the specific teaching process, theoretical study takes up the majority of the total class hours, leaving insufficient time to practice. As for media literacy education, in order to reach better teaching effect, making students participate in the process of media activities is the best teaching model. Moreover, the development of communication media and the richness of information product guarantee the implementation of this teaching model. We can see from this that they have certain difference in teaching mode. Where the content is consistent, such difference can complement each other, so as to reach the purpose of common education.

\section{Consistency of Educational Purposes}

The essence media literacy education lies in teaching the method of audience decoding, namely to get rid of the impact by media information representation through systematic and professional analysis so as to realize the clear understanding of communicator intent. [3] Analyzing the behavior of communicator is also one of the main contents of Media Criticism course, and also one of the purposes of media criticizes practical activities. Therefore, they have high consistency in terms of education purpose.

\section{CONCLUSION}

We can find from the discussion of the whole article, for the students of this major, opening Media Criticism course means establishing an ideal theoretical teaching platform for them to conduct media literacy education. Inset the content of media literacy education in the process of teaching the professional knowledge through the form of course teaching, which achieves the teaching purpose and broadens the range of students' knowledge; in addition, media literacy education enriches the content of Media Criticism course; Media Criticism course not only involves the media, media work and even the media worker, almost includes the aspects involved in media literacy education. They have consistency in terms of education purpose and education content, and complement each other in terms of form, which is an ideal mutual aid teaching mode. Based on the above analysis, the media literacy education can be performed in the teaching process of Media Criticism course, to achieve the purpose of enhancing students' media literacy level. As a result, there is certain possibility of the integration between them.

\section{REFERENCES}

[1] Zhang Zhi'an. Interpretation of Media Literacy Education, Media Observer, vol. 4, pp. 23-24, April.2005.

[2] Zhang Zhi'an, Shen Guolin. Review and Evaluation of the Research on Chinese Media Literacy, vol.5, 2004.

[3] Wu Yan. Connotation and Significance of the Media Literacy Education for the College Students in New Media Era, vol. 4,2016, p. 150. 